\title{
An unusual intracardiac image
}

\author{
Zineb Lahlou, Soundousse Salimi, Fatima Dehbi \\ Ibn Rochd University Hospital, Aberrahim Harouchi Children Hospital, Pediatric II Department, Hassan II Medicine University, Casablanca, Morocco \\ Correspondence to Dr Soundousse Salimi, salimi3006@gmail.com
}

\section{Summary}

One of the most serious complications in cardiovascular surgery is the unintentional deposit of material and surgical instruments. Very few articles portray these complications in children. This is not the case with regard to interventional and surgical cardiovascular procedures in adults. We report a case concerning a cystic heart image related to a cardiac iatrogenic foreign body in a girl of 14 years. She has been operated 13 years ago for patent ductus arteriosus and aortic stenosis and currently she is admitted for a cyanosis and a dyspnoea.

\section{BACKGROUND}

- To report the discovery of an unusual intracardiac image secondary to an iatrogenic foreign body. This kind of observation is rarely witnessed in children's cardiovascular surgery.

- Our observation is also of note because of intracardiac foreign body ageing.

- To remember to strive to discover the aetiology of dyspnoea and cyanosis in children, taking account of their history.

\section{CASE PRESENTATION}

A 14-year-old girl was referred to a tertiary children's hospital with an intracardiac mass for investigative aetiology.

She lives in a rural area and has a long history of patent ductus arteriosus and aortic valve stenosis operated at the age of one and a half in another hospital. She has had several hospitalisations for dyspnoea, and suffered from cyanosis of her lips and extremities. During the last hospital stay, an intracardiac mass was discovered and the patient was referred to us.

The history reveals that dyspnoea and cyanosis has progressively emerged since the age of 2 years, affecting her daily life and inhibiting her schooling with symptoms worsening recently.

Examination revealed a poor general health; she was exhausted, afebrile and bradycardic. Her dyspnoea was stage 4 of New York Heart Association with cyanosis of the lips and saturation was $86 \%$ in room air. She had also a chest deformity, a systolic murmur at the aortic focus radiating to the back and neck vessels.

\section{INVESTIGATIONS}

A chest x-ray, a transthoracic echocardiography and a chest MRI were performed.

Chest radiography (figure 1) shows a dorsal scoliosis to left convexity, a cardiomegaly, a lower lobe condensation and a diffuse bronchial syndrome.

Transthoracic echocardiography confirms the presence of a huge cystic intrapericardial mass. Thoracic MRI (figures 2A and B) showed a cracked intrapericardial cyst with intracystic haemorrhage and a minimal

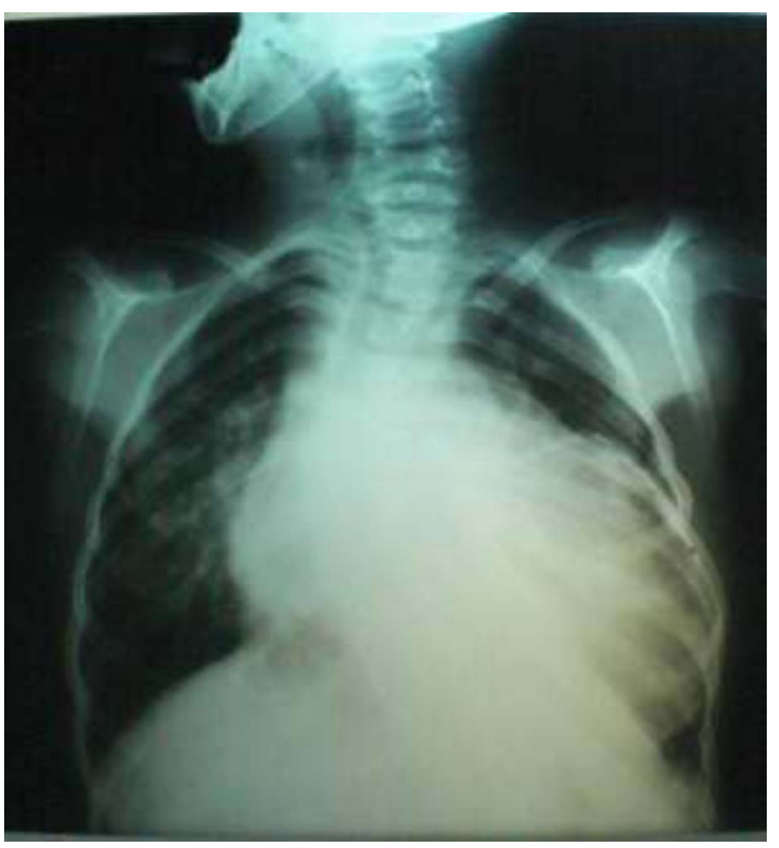

Figure 1 Chest x-ray: dorsal scoliosis, cardiomegaly, lower lobe condensation and bronchial syndrome.

haemopericardium, all leading to a collapse of the right and left ventricle.

\section{DIFFERENTIAL DIAGNOSIS}

The main diagnostic hypothesis is a hydatid cyst on first on account of the rural origins of the patient; and secondarily a cardiac tumour. A hydatid serology was negative and abdominal ultrasound showed no hydatid abdominal localisation.

\section{TREATMENT}

Surgery is deemed necessary in order to explore this lesion and to make diagnostic and therapeutic decisions.

\section{OUTCOME AND FOLLOW-UP}

Surgical exploration led to the surprising discovery of an abscess due to a forgotten compresse in the intracardiac 


\section{BMJ Case Reports}

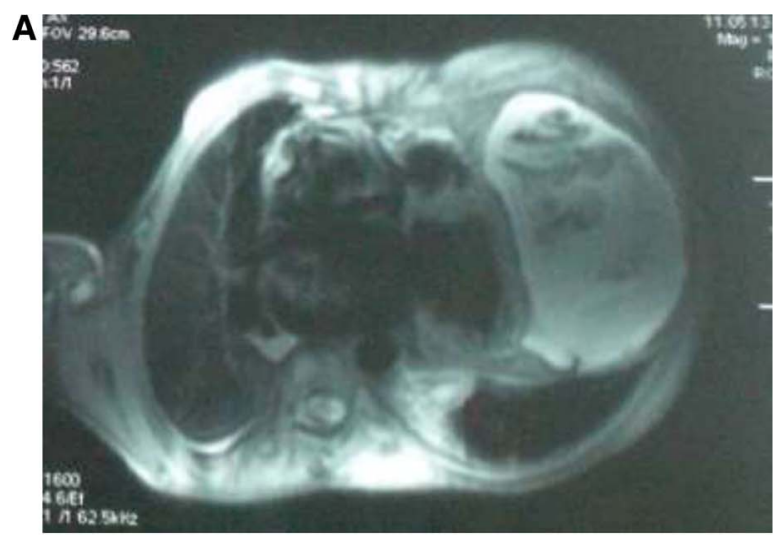

B

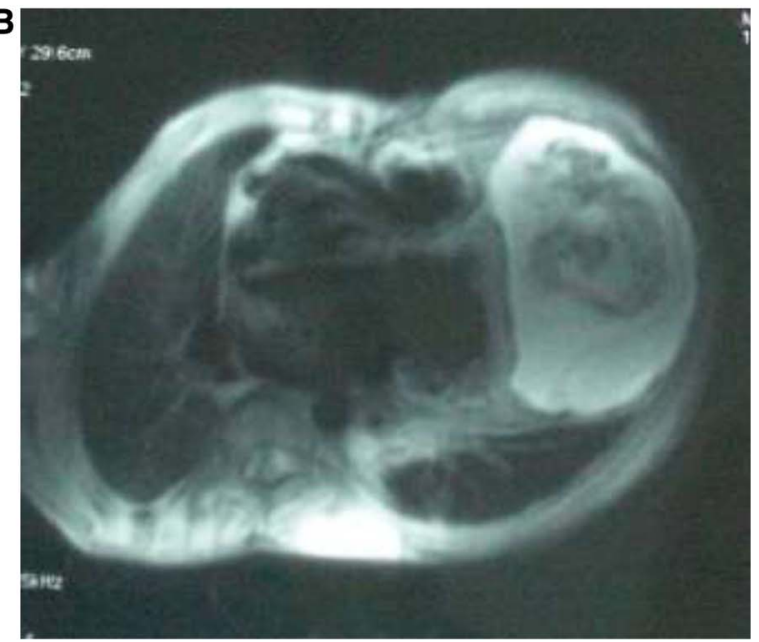

Figure $2 \quad(A ; B)$ Thoracic MRI: cracked intrapericardial cyst with intracystic haemorrhage and a minimal hemopericardium.

13 years ago during the first surgery. A sample extracted intraoperatively was sterile, leading to a conclusion of asepetic abscess which was then drained. The postoperative was uneventful with subsequent clinical and radiological improvement.

\section{DISCUSSION}

In children, few observations of cardiac foreign bodies due to non-traumatic causes are reported. Indeed, the cases described are customarily related to chest trauma in road accidents or in attacks by knives or guns. ${ }^{1}$ Our case is noteworthy by virtue of the foreign body and mainly how long it had been in the intracardiac region because it was discovered after 13 years of surgery.

Intracardiac opacity can sometimes pose diagnostic problems. However, integrating a patient's history and surgical history, a surgical complication must be suspected regardless of her age and should lead to surgical exploration. Our patient was the victim of complication resulting from the forgetting of an iatrogenic foreign body during cardiac surgery either due to negligence or by mere carelessness. In addition, she has not benefited from rapid, complete and correct exploration of this complication; surgical exploration was never indicated in the evidence of radiological image and the persistence of symptoms for many years.

The forgetting of surgical instruments or material (compresse, gauze, etc) is a serious complication ${ }^{2}$ but that is rare and may be responsible for various complications such as abscess formation. The development can be insidious before the first clinical symptoms. Indirect signs such as a chest deflection, the onset of scoliosis, the occurrence of dyspnoea, cyanosis or alteration of general condition warrant attention.

In surgical practice, zero risk does not exist. ${ }^{3}$ Nevertheless, the surgeon is required to be accurate in his procedures. ${ }^{4} \mathrm{He}$ should ensure maximum safety ${ }^{3}$ and take the necessary and sufficient precautions to carry out surgery according to proper practice from beginning to end of intervention. In case of damage ancillary to surgery, the surgeon must address the complication with prompt and correct diagnosis, provide appropriate treatment and inform the patient and his family. ${ }^{4}$ We agree with Sanjuán who claims that forgetting surgical equipment is very harmful for patients and also for training of residents. ${ }^{2}$

\section{Learning points}

In the evidence of a history of surgery, a surgical complication is indicated regardless of how long ago the intervention took place and should lead to surgical exploration.

- The surgeon is required to be accurate in his procedures.

- Always look for an underlying aetiology to explain symptoms demonstrated by child especially if signs persist.

\section{Competing interest None.}

Patient consent Obtained.

\section{REFERENCES}

1. Linard C, Marques P, Bezon E, et al. Pericardial foreign body: an unusual cause of chest pain in children. Arch Pediatr 2010;17:1682-4.

2. Sanjuán RS, Enríquez Zarabozo E, Moreno Hurtado C, et al. Intrakidney-catheter. Post pyelo-plasty complication. Cir Pediatr 2009; 22:106-8.

3. Vayre P. Gestion des risques en pratique chirurgicale : la sérénité retrouvée. Ann Chir 2000;125:925-8.

4. Rougé-Maillart C, Jousset N, Gaudin A, et al. Faut-il reconnaitre I' ' aléa chirurgical'? Médecine Droit 2008;2008 43-7. 
Copyright 2012 BMJ Publishing Group. All rights reserved. For permission to reuse any of this content visit http://group.bmj.com/group/rights-licensing/permissions.

BMJ Case Report Fellows may re-use this article for personal use and teaching without any further permission.

Please cite this article as follows (you will need to access the article online to obtain the date of publication).

Lahlou Z, Salimi S, Dehbi F. An unusual intracardiac image. BMJ Case Reports 2012;10.1136/bcr-2012-006889, Published XXX

Become a Fellow of BMJ Case Reports today and you can:

- Submit as many cases as you like

- Enjoy fast sympathetic peer review and rapid publication of accepted articles

- Access all the published articles

- Re-use any of the published material for personal use and teaching without further permission

For information on Institutional Fellowships contact consortiasales@bmjgroup.com

Visit casereports.bmj.com for more articles like this and to become a Fellow 